\title{
The use of disorientation of the plum moth in the conditions of chemical protection of the orchard
}

\author{
Olya Zelenskaya, and Valeriy Orlov* \\ Federal State Budgetary Scientific Institution "National Center of Grain named after P.P. \\ Lukyanenko", Krasnodar, 350012, Russia
}

\begin{abstract}
Disorientation of the plum moth (Grapholita funebrana Treitschke) under the conditions of chemical protection of the garden was carried out using dispensers (Z8DDA, $16.7 \mathrm{mg}$ ) produced by ZAO Shchelkovo Agrokhim. Dispensers were placed at a tree trunk at a height of $1.5-2 \mathrm{~m}$ with an application rate of 500 per hectare. The study was carried out on three plots of a 1 ha plum orchard: a plot with chemical treatments and with disorientation, an area with chemical treatments, without disorientation, and an area without chemical treatments and without disorientation. The effectiveness of disorientation at a high abundance during the flight peaks of the second and third generations of the pest ranged from $100 \%$ to $92-93 \%$. The effectiveness of disorientation, together with the chemical protection of the garden in comparison with untreated area, showed higher results - in the first two months, the efficiency ranged from 100 to $98 \%$, and during the periods of the 2nd and 3rd flight peaks of the pest (with a flight intensity of $136-120$ individuals per trap) did not fall below $96 \%$.
\end{abstract}

\section{Introduction}

The economic significance of the plum moth (Grapholita funebrana Treitschke) is quite large, it damages cherry plums, blackthorns, plums, apricots, peaches, flowering plum, bird cherry of Maksimovich, cherry, including Japanese or Korean, shrub or steppe and felt, cherry or sogssurian pear, and was noted in the Dahurian rosehip and in the hawthorn $[1,2$, 3]. Damage to the plum crop is estimated at $70-80 \%[1,4]$. According to our observations, the pest can reduce the market value of almost the entire crop.

The species, according to the map presented by CABI, is widespread in the Palaearctic and in the Indo-Malay region [5], unfortunately, for the territory of Russia, this global map rather doubtfully reflects the real distribution of the species. But the area of the pest and the zones of damage are shown quite convincingly on the map of the agroatlas [1], analyzing which it can be seen that in the Russian Federation it is the most harmful in the steppe zone. In the Krasnodar Region, the actual data on the distribution and harmfulness were given in special works [6].

\footnotetext{
*Corresponding author: elater@mail.ru
} 
In recent years, due to the shift in climatic zones and warming in the European Russian, many species have noticeably moved to the north. So in the Moscow region, it was noted that the plum moth develops already in 2 generations [7]; later, researchers noted the precedent of the second generation of the pest near the 60th parallel of northern latitude. Thus, the significance of the species increases sharply due to the expansion of the zone of harmfulness.

The genetic possibilities of controlling this pest are very modest, it is noted that wood species and varieties differ in the degree of damage, but there are no immunity plum genomes in production $[4,8,9]$.

In nature, the species is controlled by braconids: Ascogaster quadridentana (Wesm.), Apanteles laspeyresiellus (Papp); ichneumonids: Pimpla spuria (Grav.), Pimpla turionellae (L.), Lissonota carbonaria Holm., Enytus apostata (Grav.), Liotryphon punctulatus (Ratz.), Liotryphon caudatus (Ratz.), Pristomerus weakrator (Panz.) and Diadegma armillata (Grav.), Dolichomitus tuberculatus (Geoffr.) [10,11] and chalcides: Copidosoma varicorne Nees, Hyssopus nigritulus Zett., Tetrastichus sp., Trichogramma sp., T. dendrolimi Mats., T. cacaeciae March., T. evanescens Westw. [12]. If the effectiveness of T. dendrolimi Mats. used in IPM technologies is still acceptable [13], the role of natural parasites in limiting the pest population, due to the increasing economic importance of the harmful object, is clearly insufficient and pushes researchers to search for other control methods, including the use of chemicals. Since one of the universal methods at present is insecticide treatment, but their massive use regularly leads to an increase in resistance, the search for new active substances for control purposes continues.

In recent years, the search for new active substances for the creation of insecticides in order to optimize chemical pest control measures aimed at controlling the larval phase has been carried out quite widely [14]. But the early control of pests in the adult phase has a tempting advantage due to the complete exclusion of the appearance of the harmful phase on the fruits. Since young larvas that have begun to take root in the fruit are able to reduce the saleable condition due to the release of gum from damage, protection at earlier stages is advisable. This will reduce the harm from larvas hatching from eggs, but because treatment during oviposition by many groups of drugs is ineffective, and their use at the beginning of hatching, with extended periods of hatching of larvae from eggs, is often economically unjustified and is available only to highly trained specialists.

Therefore, the use of drugs with ovicidal action and the control in the phase of the pest's imago still have great research prospects. The largest number of works on the use of control during the flight of imago is associated with the use of pheromones [15, 16, 17In general, the method appeals to the agricultural service, both due to the duration of action and the economy of use, and recent studies have already made it possible to develop a bait with a sufficiently long period of action that allows the use of single-use dispensers for the plum moth for the entire period of crop protection [18].

On the other hand, the use of pheromones is traditionally welcomed by ecologists, because allows you to solve many problems in the organic garden $[9,19]$. In Switzerland, half of 16 mating disorder experiments using Z8DDA were successful [20].

This paper discusses the role of the method of disorientation of the plum moth Grapholita funebrana Treitschke using long-term dispensers for different pest numbers.

\section{Materials and methods}

The studies were carried out in the course of finalizing the instructions for applying the method of disorientation of the plum moth in an industrial garden. The site was located in the Krasnoarmeisky district of the Krasnodar Region in the garden of the farm Prototsky. Dispensers and pheromone traps for the plum moth were provided by ZAO Shchelkovo 
Agrokhim. The research period is March - September. Pheromone dispensers (16.7 mg, Z8DDA) were hung in the garden during the beginning of the mass flowering of the plum (cherry plum), when the first generation of butterflies began to emerge Depending on the configuration and tree planting scheme of the garden, at least 500 dispensers must be placed per hectare. Pheromone dispensers (rings) are placed on the tree closer to the center of the trunk at a height of $1.5-2 \mathrm{~m}$.

To disorientate the plum moth, three garden plots of plum plantations, each 1 hectare in size, inhabited by the pest, were selected:

I - area with chemical treatments and with the method of disorientation;

II - area with chemical treatments, without disorientation method;

III - area without chemical treatments and without a disorientation method.

To determine the effectiveness of disorientation, control pheromone traps were hung on the experimental sites. One trap is enough for 5 hectares. Also, to determine the biological effectiveness of the disorientation method, control traps were hung on clean, pesticide-free areas of the plum garden.

\section{Results and discussion}

The imago of the plum moth (Grapholita funebrana Treitschke) appear shortly after the plum blossom. The average calendar period of mass flight in the south falls in the third decade of May, in the forest-steppe zone and Polesye - in the first decade of June [8-9]. The life span of butterflies ranges from 4 to 15 days. Butterflies of the second generation emerge in the second or third decades of June; eggs are laid on fruits [6].

To determine the beginning of flight of the plum moth in the third decade of March, control traps were hung on the experimental plots of the garden. Warm winter and early spring in the Krasnoarmeisky district of the Krasnodar Region during the study period contributed to the early pupation of overwintered larvaes and the emergence of the plum moth from wintering sites. The flight of the first generation of the pest began in the first ten days of April (the beginning of cherry plum blossoming). In this regard, the method of disorientation was laid down at the beginning of the second decade of April last year. Observations and counts were carried out every two weeks during the entire flight period of the pest. The plum moth flight continued until the end of September. The last single individuals in the control were caught in November.

At each disorientated test site, control traps were posted to determine the effectiveness of disorientation in comparison with the control. To control the effectiveness of the disorientation method, a site with cherry-plum plantings was selected, where all chemical treatments were excluded, including the use of the disorientation method. On the control plot of the garden, control traps were also hung out. Experimental plots with disorientation were subjected to chemical treatments planned on the farm, including insecticidal ones. To determine the effectiveness of the disorientation method in combination with insecticidal treatments, an area with only insecticidal treatments was allocated.

The results of trapping in control traps on the plots when compared with the control under the conditions of chemical protection of the garden show that the efficiency of disorientation under conditions of a high number of pests ranged from $100 \%$ to $92-93 \%$ during the peaks of flight of the second and third generations of the pest (Fig.). The calculation of the effectiveness of using the method of disorientation of the plum moth in conjunction with the chemical protection of the garden relative to the uncultivated area of the garden showed higher results. The efficiency for the first two months ranged from 100 to $98 \%$ and did not fall below $96 \%$ during the periods of the 2 nd and 3rd peaks of flight of the plum moth, when the number of butterflies reached $136-120$ ind./trap at the peaks of flight of the second and third generations respectively. 


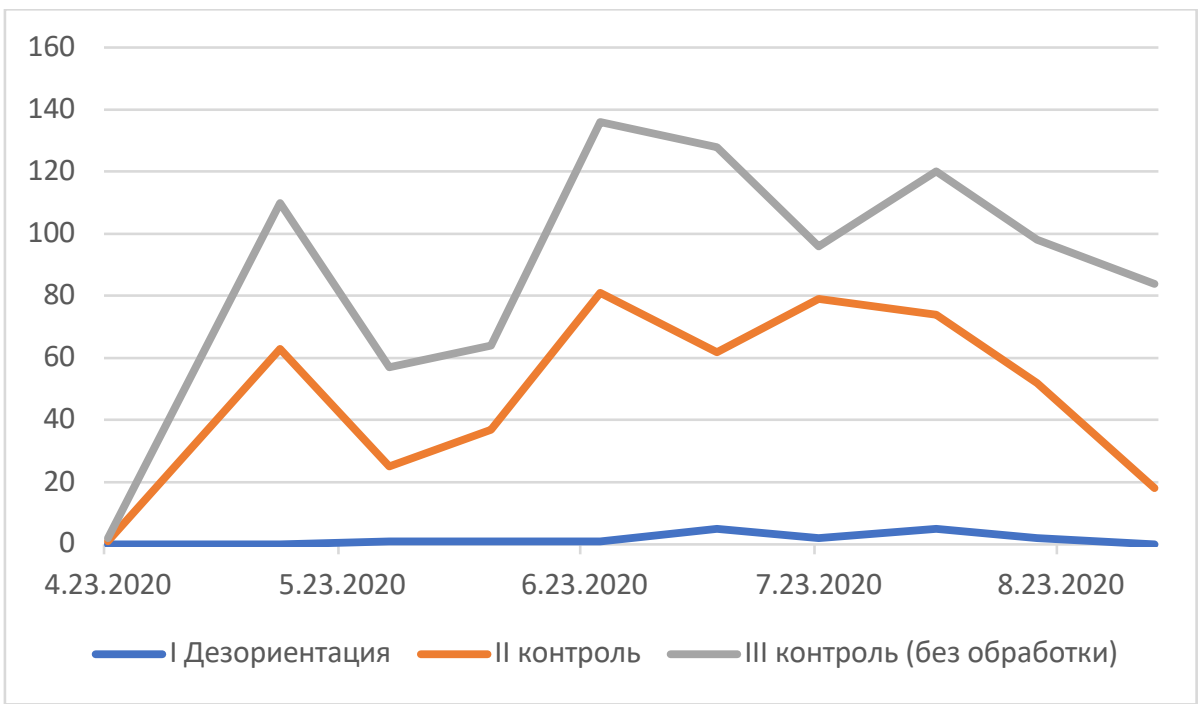

Fig. Disorientation of the plum moth in an industrial garden

I - area with chemical treatments and with the method of disorientation;

II - area with chemical treatments, without disorientation method;

III - area without chemical treatments and without a disorientation method.

Thus, the use of disorientation of the plum moth (16.7 mg, Z8DDA, 500 dispensers/1 ha) in an industrial garden makes it possible to increase the role of chemical protection of the plum and control the pest with the effectiveness of the method from 100 to $92 \%$, depending on the number of the pest.

\section{References}

1. Laspeyresia funebrana Treitschke - Plum Fruitworm, Plum Fruit Moth. http://www.agroatlas.ru/en/content/pests/Laspeyresia funebrana/index.html

2. Annotated catalogue of the insects of Russian Far East. Volume I. Hymenoptera. (Vladivostok: Dalnauka, 2012)

3. T.M. Gilligan, M.E. Epstein, Tortricids of Agricultural Importance (UMass Amherst, Colorado, 2011).

4. R. Rizzo, V. Farina, F. Saiano, A. Lombardo, E. Ragusa, G. Lo Verde, Insects, 10(12), 1-16 (2019) http://dx.doi.org/10.3390/insects10120444

5. CABI. Invasive Species Compendium. Grapholita funebrana (red plum maggot) // CAB International, 2021. https://www.cabi.org/isc/datasheet/29901\#toDistributionMaps

6. S. Prah, I. Mishchenko, M. Podgornaya, Fruit growing and viticulture of South Russia, 35(5), 131-141 (2015)

7. A.S. Zeynalov, Agric. Biol., 53(5), 1080-1088 https://doi.org/10.15389/agrobiology.2018.5.1080eng

8. W. Wu, F. Chen, K. Yeh, J. Chen, Biology 8, 2 (2018) http://dx.doi.org/ $\underline{10.3390 / \text { biology } 8010002}$

9. Z.S. Grzyb, E. Rozpara, Acta Hortic. 968, 133-136 https://doi.org/10.17660/ActaHortic.2012.968.18

10. N.N. Velcheva, A. Atanassov, Bulgarian Journal of Agricultural Science, 22(2), 272277 (2016) https://www.researchgate.net/publication/301678184

11. J. Kolarov, Journal of National Park Research, 10(1), 1-181 (2019). 
12. Y. Qu, X. Chen, F. Zhang, S. Wang, L.S. Monticelli, N. Desneux, D. Huijie, R. Ramirez-Romero, Entomologia Generalis, 40(4), 385-395 (2020) http://dx.doi.org/10.1127/entomologia/2020/1059

13. The Natural History Museum, London. Universal Chalcidoidea Database. https://www.nhm.ac.uk/our-

science/data/chalcidoids/database/namedHost.dsml?HOSGENUS=Cydia\&HOSSPECIE $\underline{\mathrm{S}=\text { funebrana\&\& }}$

14. R. Rizzo; G. Lo Verde, A. Lombardo, New Medit, 11(4), 68-70 (2012)

1. https://www.researchgate.net/publication/258257029

15. S.A. Steffan, E.M. Chasen, A.E. Deutsch., A. Mafra-Neto, J. Ins. Sci., 17(2), 54, (2017) https://doi.org/10.1093/jisesa/iex025

16. R. Rizzo, G. Lo Verde. Progetto per lo sviluppo dell'agricoltura biologica in Sicilia (Qanat Edizioni, Italy, 2011).

17. S.A. Steffan, E.M. Chasen, A.E. Deutsch, A. Mafra-Neto, J. Ins. Sci., 17(2), 1-6 (2017) https://doi.org/10.1093/jisesa/iex025

18. G. Lo Verde, S. Guarino, S. Barone, R. Rizzo, Insects, 11(9), 1-14. (2020) https://doi.org/10.3390/insects11090589

19. H. Kutinkova, V. Dzhuvinov, J. Samietz, V. Veronelli, A. Iodice, C. Bassanetti, In: M. Tasin, Z. Karpati, M. Tóth (edd.) IOBC/WPRS Bulletin, 72, 53-57 (Budapest, 2011)

20. P. J. Charmillot, C. Blaser, M. Baggiolini, H. Arn, B. Delley, CABI. Invasive Species Compendium (2021) https://www.cabi.org/isc/abstract/19820594701 